\title{
Coexistence of Aldosterone-Producing Adrenocortical Adenoma and Pheochromocytoma in an Ipsilateral Adrenal Gland
}

\author{
NORIKO SAKAMOTO, KATSUYOSHI TOJO, TAKATOSHI SAITO, KEI FUJIMOTO, TSUYOSHI ISAKA, \\ NAOKO TAJIMA, KEIICHI IKEDA*, HIRONORI YAMADA**, NOZOMU FURUTA** \\ AND HIRONOBU SASANO*** \\ Division of Diabetes and Endocrinology, Department of Internal Medicine, The Jikei University School of Medicine, 3-25-8, \\ Nishishinbashi, Minato-ku, Tokyo 105-8461, Japan \\ *Department of Pharmacology, The Jikei University School of Medicine, 3-25-8, Nishishinbashi, Minato-ku, Tokyo 105-8461, Japan \\ **Department of Urology, The Jikei University School of Medicine, 3-25-8, Nishishinbashi, Minato-ku, Tokyo 105-8461, Japan \\ ***Department of Pathology, Tohoku University School of Medicine, 2-1 Seiryocho Aoba-ku, Sendai, Miyagi 980-8575, Japan
}

\begin{abstract}
A 40-year-old female, diagnosed as essential hypertension, demonstrated a $2 \mathrm{~cm}$ mass in left adrenal gland by computed tomography without abnormal endocrinological findings. ${ }^{131} \mathrm{I}$-adosterol and ${ }^{123} \mathrm{I}$-metaiodobenzylguanidine (MIBG) scintigraphy at 39 years of age showed no abnormal accumulation. Follow up ${ }^{131}$ I-adosterol scintigraphy performed one year later showed apparently abnormal uptake and slightly elevated uptake in left adrenal gland. Her physical examination was unremarkable except for mild hypertension. Routine blood chemistry was normal except for hypokalemia. Endocrinological date revealed suppressed plasma renin activity, and elevated plasma aldosterone concentration, and noradrenalin levels. Serial T2-weighted magnetic resonance imaging clearly demonstrated two distinct tumors. Furthermore, selective adrenal venous sampling with intravenous ACTH infusion indicated aldosteroneproducing adrenocortical adenoma (APA) in left adrenal gland. During operation of adrenal tumor, blood pressure elevated markedly and complication of pheochromocytoma (PC) was suspected. Immunohistochemical findings after left adrenolectomy revealed that the adrenal mass was compatible with APA and PC. Risk of operation against undiagnosed $\mathrm{PC}$ is very high and, therefore, it must be diagnosed before surgery. Herein, we present an extremely rare case of the simultaneous occurrence of both APA and PC in an ipsilateral adrenal gland.
\end{abstract}

Key words: Adrenal tumor, Aldosterone-producing adenoma, Pheochromocytoma, Hypertension, Serial MRI

(Endocrine Journal 56: 213-219, 2009)

\begin{abstract}
ALTHOUGH aldosterone-producing adenoma (APA) and pheochromocytoma (PC) are fairly common, the simultaneous occurrence of both tumors in an ipsilateral adrenal gland is extremely rare, and few cases have been reported to date [1-4]. Few cases demonstrated the clinical features of both APA and PC. Wilkins et al. reported a patient who had no clinical features of APA, although the endocrinological data suggested

Received: July 28, 2008

Accepted: November 5, 2008

Correspondence to: Katsuyoshi TOJO, Division of Diabetes and Endocrinology, Department of Internal Medicine, The Jikei University School of Medicine, 3-25-8, Nishishinbashi, Minato-ku, Tokyo 105-8461, Japan
\end{abstract}

hypokalemia [1]. Hsieh et al. reported a patient who had no clinical features of PC, although the endocrinological data suggested increase in vanillyl mandelic acid (VMA) [2]. In only two cases among them was the coexistence of APA and PC properly diagnosed before surgery [4]. In the present case, in addition to the rarity of complication of PC with APA, we initially diagnosed as primary aldosteronism with double adrenal mass, and failed to diagnose as PC. Because risk during surgery for undiagnosed PC is very high $[5,6]$, we would like to present an additional case confirmed by endocrinological and immunohistochemical examinations. 


\section{Case report}

A 40-year-old woman was referred to an endocrinology clinic for further examination for a suspected adrenal tumor. She had no relevant family history. When she was 19 years old, she consulted a gynecologist for hypermenorrhea and painful menses, and underwent leiomyomectomy for uterine myoma when she was 28 and 32 years old. After hormonal therapy for infertility was started at 34 years of age, she gradually began to put on weight. In 2002, at age 37 , she was referred to a cardiovascular clinic. Endocrinological findings revealed increased plasma aldosterone concentration (PAC) as well as decreased plasma renin activity (PRA) (PAC: $13 \mathrm{ng} / \mathrm{dl}$; PRA: $0.1 \mathrm{ng} / \mathrm{ml} / \mathrm{hr}$; PAC/PRA: 130). Plasma catecholamine levels were also increased: adrenalin (A): $24 \mathrm{pg} / \mathrm{ml}$; noradrenalin (NA): $913 \mathrm{pg} / \mathrm{ml}$; dopamine (DA): $25 \mathrm{pg} / \mathrm{ml}$; VMA: $9.8 \mathrm{ng} / \mathrm{ml}$; but abdominal echo demonstrated no adrenal mass. Therefore she was diagnosed as essential hypertension and was treated with antihypertensive drugs on an outpatient basis. In June 2004, at age 39, she underwent an operation again for uterine adenomyosis. Left adrenal mass $(2 \mathrm{~cm})$ was incidentally demonstrated by postoperative abdominal computed tomography (CT), after which she was referred to the outpatient clinic of urology. ${ }^{131} \mathrm{I}$-adosterol scintigraphy (without dexamethasone suppression) and ${ }^{123}$ I-MIBG scintigraphy showed no abnormal accumulation with normal basal hormone levels: PAC: $10 \mathrm{ng} / \mathrm{dl}$; PRA: $0.5 \mathrm{ng} / \mathrm{ml} / \mathrm{hr}$; A: $32 \mathrm{pg} / \mathrm{ml}$; NA: $903 \mathrm{pg} / \mathrm{ml}$; DA: $16 \mathrm{pg} /$ $\mathrm{ml}$; and plasma ACTH: $15.7 \mathrm{pg} / \mathrm{ml}$; cortisol: $17.5 \mu \mathrm{g} / \mathrm{dl}$; dehydroepiandrosterone sulfate (DHEA-S): $563 \mathrm{ng} / \mathrm{ml}$. ACTH and cortisol levels were normally suppressed by dexamethasone $1 \mathrm{mg}$ (ACTH: $5.0>\mathrm{pg} / \mathrm{ml}$, cortisol; $2.4 \mu \mathrm{g} / \mathrm{dl}$ ). Thereafter she has been followed up on an outpatient basis. Abdominal CT revealed her adrenal mass had grown to $3 \mathrm{~cm}$ in diameter in March 2005, so we suspected malignancy. At that time, plasma cortisol level was not adequately suppressed by dexamethasone $1 \mathrm{mg}$ and $8 \mathrm{mg}$ ( $1 \mathrm{mg}$ : ACTH: $5.0>\mathrm{pg} / \mathrm{ml}$; cortisol: $5.5 \mu \mathrm{g} / \mathrm{dl}$; $8 \mathrm{mg}$ : ACTH: $5.0>\mathrm{pg} / \mathrm{ml}$; cortisol: $6.8 \mu \mathrm{g} / \mathrm{dl}$ ). She was referred to an endocrinology clinic for suspected Cushing's syndrome and was hospitalized for further examination in June 2005.

The patient was $154 \mathrm{~cm}$ tall, weighed $69 \mathrm{~kg}$, and was obese with a BMI of $29.1 \mathrm{~kg} / \mathrm{m}^{2}$. Her body temperature was $36.7^{\circ} \mathrm{C}$ with a heart rate of 68 beats per minute. Blood pressure was $152 / 92 \mathrm{mmHg}$. No typi-
Table 1. Endocrinological Examination on Admission

\begin{tabular}{lcc}
\hline & Patient's date & normal range \\
\hline PAC $(\mathrm{ng} / \mathrm{dl})$ & 20 & $2.99-15.9$ \\
PRA $(\mathrm{ng} / \mathrm{ml} / \mathrm{hr})$ & 0.1 & $0.3-2.9$ \\
Cortisol $(\mu \mathrm{g} / \mathrm{dl})$ & 17.5 & $4.0-18.3$ \\
DHEA-S $(\mathrm{ng} / \mathrm{ml})$ & 372 & $250-1950$ \\
A $(\mathrm{pg} / \mathrm{ml})$ & 43.0 & $100>$ \\
NA $(\mathrm{pg} / \mathrm{ml})$ & 1136 & $100-450$ \\
DA $(\mathrm{pg} / \mathrm{ml})$ & 29 & $20>$ \\
ACTH $(\mathrm{pg} / \mathrm{ml})$ & 14.9 & $7.4-55.7$ \\
GH $(\mathrm{ng} / \mathrm{ml})$ & 0.15 & $0.28-1.64$ \\
IGF-I $(\mathrm{ng} / \mathrm{ml})$ & 170 & $98-245$ \\
LH $(\mathrm{mIU} / \mathrm{ml})$ & 7.6 & $2.29-16.93$ \\
FSH $(\mathrm{mIU} / \mathrm{ml})$ & 9.0 & $3.01-14.72$ \\
PRL $(\mathrm{ng} / \mathrm{ml})$ & 44.1 & $6.12-30.54$ \\
$<\mathrm{Urine}>$ & & \\
Cortisol $(\mu \mathrm{g} /$ day $)$ & 21.6 & $30-100$ \\
$17 \mathrm{OHCS}(\mathrm{mg} / \mathrm{day})$ & 4.4 & $2.2-7.3$ \\
$17 \mathrm{KS}(\mathrm{mg} / \mathrm{day})$ & 3.7 & $2.4-11.0$ \\
CPR $(\mathrm{mg} / \mathrm{day})$ & 57.4 & $20.5-198$ \\
NTX & 35.4 & $9.3-54.3$ \\
$(\mathrm{nmolBCE} / \mathrm{mmol} \cdot \mathrm{CRE})$ & & \\
\hline
\end{tabular}

IGF-1; insulin-like growth factor

17-OHCS; 17-hydroxycorticosteroid

17-KS; 17-ketosteroid CRP; C-peptide

NTX; crosslinked N-telopeptide of type I collagen

cal signs of Cushing's syndrome, such as moon face or buffalo hump, were found. While some vascular fragility was noted on the skin, no skin striae were found. No other abnormal physical findings were found.

Hematological examination revealed no abnormality except hypokalemia with a serum potassium level of $3.1 \mathrm{mmol} / \mathrm{l}$. Echocardiography revealed no abnormal findings. Endocrinological findings were as follows: an increased PAC as well as decreased PRA was noted (PAC, PRA and PAC/PRA were $20 \mathrm{ng} / \mathrm{dl}, 0.1 \mathrm{ng} / \mathrm{ml} /$ $\mathrm{hr}$, and 200, respectively). Additionally, serum PRL level was slightly elevated; besides, of the three fractions of catecholamine, NA and DA were increased at $1136 \mathrm{pg} / \mathrm{ml}$ and $29 \mathrm{pg} / \mathrm{ml}$, respectively, while plasma ACTH and cortisol levels were normal (Table 1). Diurnal variations in plasma ACTH and cortisol levels were maintained. However, plasma cortisol level was not suppressed by dexamethasone with dexamethasone $1 \mathrm{mg}$ or $8 \mathrm{mg}$. In the furosemide standing test, no increased PRA was noted (Table 2).

Radiological findings were as follows: a hypodensity mass measuring $2.5 \times 2.5 \mathrm{~cm}$ was noted in the left adrenal gland on abdominal CT, and this mass was de- 
Table 2. Endocrinological Provocation Tests Diurnal variatin of plasma ACTH, cortisol levels

\begin{tabular}{rccc}
\hline \multicolumn{1}{c}{ Time $(\mathrm{hr})$} & $8: 00$ & $16: 00$ & $23: 00$ \\
\hline ACTH $(\mathrm{pg} / \mathrm{mL})$ & 14.9 & 7.7 & $5.0>$ \\
Cortisol $(\mu \mathrm{g} / \mathrm{dL})$ & 13.8 & 8.1 & 6.0 \\
\hline
\end{tabular}

Dexamethazone suppression test

\begin{tabular}{rcll}
\hline \multicolumn{1}{c}{ Dose $(\mathrm{mg})$} & 0 & \multicolumn{1}{c}{1} & \multicolumn{1}{c}{8} \\
\hline ACTH $(\mathrm{pg} / \mathrm{mL})$ & 14.9 & $5.0>$ & $5.0>$ \\
Cortisol $(\mu \mathrm{g} / \mathrm{dL})$ & 13.8 & 5.6 & 4.8
\end{tabular}

\begin{tabular}{lccc}
\multicolumn{2}{l}{ Furosemide standing test } \\
\multicolumn{1}{c}{ Time (min) } & 0 & 60 & 90 \\
\hline PRA (ng/ml/hr) & 0.2 & 0.2 & 0.1 \\
PAC (ng/dl) & 14 & 21 & 25 \\
\hline
\end{tabular}

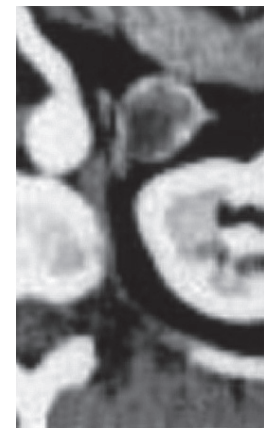

A

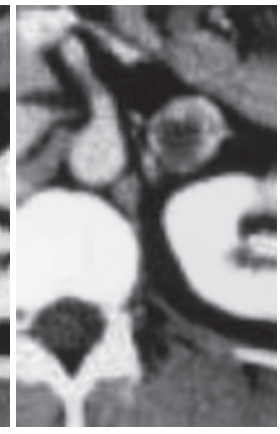

B

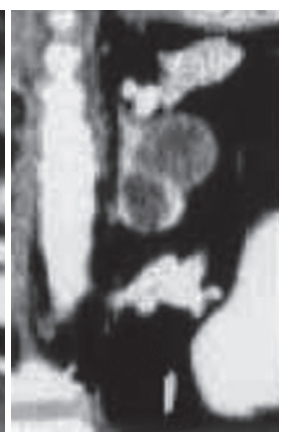

C
Fig. 1. Enhanced abdominal CT imaging. A: early. B: delay. $\mathrm{C}$ : multiplanar reconstruction

picted by multiplanar reconstruction as two different masses closely adjacent like a calabash (Fig. 1). On serial thin-slice magnetic resonance imaging (MRI), the lesion was depicted as a hypointensive mass on T1-weighted in-phase images, while, on T1-weighted out-phase images, it was depicted as a tumor with heterogenous intensity. Furthermore, T2-weighted images suggested a mixed population of tumors showing low signal intensity and extremely high signal intensity (Fig. 2). ${ }^{131}$ I-adosterol scintigraphy performed under dexamethasone suppression (dexamethasone $4 \mathrm{mg}$ / day given for 10 days) showed increased uptake in the ipsilateral adrenal and inhibited uptake in the contralateral adrenal gland. Selective adrenal venous sampling under ACTH $250 \mu \mathrm{g}$ infusion showed a significant increase in aldosterone secretion from the left adrenal gland as follows. PAC(A) (ng/dl)/cortisol (C) $(\mu \mathrm{g} / \mathrm{dl})$ and $\mathrm{A} / \mathrm{C}$ ratio: left adrenal vein 2500/515 (4.85), right adrenal vein 110/282 (0.39), inferior vena cava 44/24.3 (1.81), A/A ratio was 22.7, (left A/C)/ (right $\mathrm{A} / \mathrm{C}$ ) was 12.4 , (right $\mathrm{A} / \mathrm{C}$ )/(inferior vena cava $\mathrm{A} / \mathrm{C}$ ) was 0.22 .

Based on these findings, the patient was diagnosed as primary aldosteronism due to left adrenal tumor. At the same time, the patient was suspected of having preclinical Cushing's syndrome as well. The patient was continued on anti-hypertensive therapy (telmisartan $40 \mathrm{mg}$, hydralazine $80 \mathrm{mg}$, atenolol $25 \mathrm{mg}$ per day), and potassium replacement was not required. Finally on September 16, 2005, laparoscopic left adrenalectomy was performed. During operation, the patient showed a temporary increase in blood pressure to 200/ $120 \mathrm{mmHg}$ and co-existence of PC was suspected.

The excised adrenal gland weighed $28 \mathrm{~g}$. The left adrenal specimen contained a yellowish round mass that measured $24 \times 18 \mathrm{~mm}$, as well as a reddishbrown, well-encapsulated, hemorrhagic medullary mass that measured $19 \times 13 \mathrm{~mm}$. The attached normal adrenal tissue was markedly compressed (Fig. 3). Hematoxylin-eosin staining demonstrated that the yellowish round mass contained very few compact cells and was mainly composed of clear cells. While it had no clear membrane, the tumor mass was relatively well demarcated and was not associated with any findings of malignancy by the Weiss criteria [7]. Immunohistochemical staining showed that all steroid synthetases, $\mathrm{P} 450_{\mathrm{SCC}}, 3 \beta-\mathrm{HSD}, \mathrm{P} 450_{\mathrm{C} 21}$ and $\mathrm{P} 450_{\mathrm{C} 11}$, were expressed in the tumor tissue except $\mathrm{P} 450_{\mathrm{C} 17}$. Furthermore, the zona glomerulosa of the normal adrenal gland showed hyperplasia with no expression of $3 \beta$ HSD, which was construed as a finding of paradoxical hyperplasia associated with aldosterone overproduction [8]. No significant atrophy was found in the zona fasciculate and zona reticularis, suggesting no suppression of the hypothalamus-pituitary-adrenal (HPA) axis (Fig. 4). These findings excluded the possibility of oversecretion of cortisol from the adrenocortical tumor, leading to the diagnosis of APA. The reddishbrown mass was found to be a hemocoel-rich pleomorphic tumor expressing all relevant markers of neuroendocrine cells, i.e., chromogranin A, neuro-specific enolase, and neural cell adhesion molecule, and the diagnosis was established as PC. The Ki67 labeling index for this tumor was shown to be 4 to $5 \%$. In summary, APA and PC were thought to co-exist in the ipsilateral adrenal gland in this patient. 


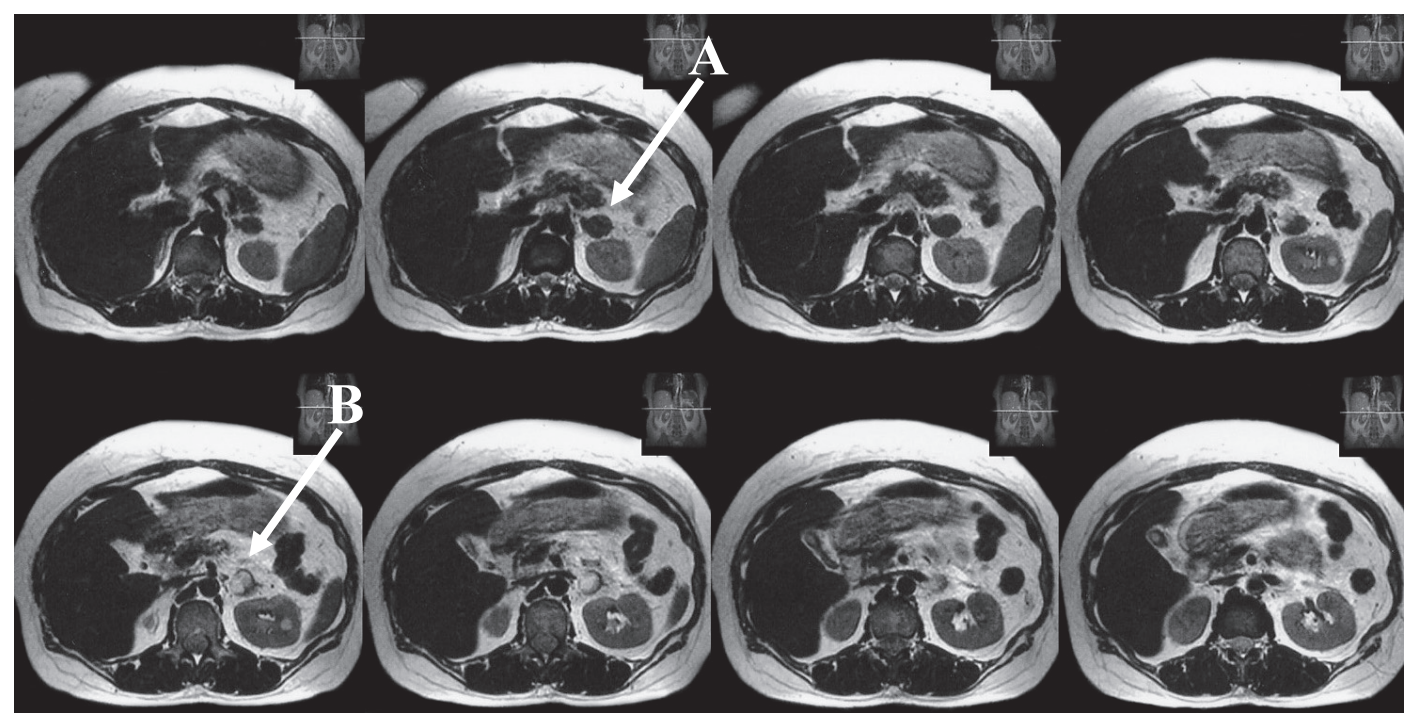

Fig. 2. Serial abdominal MRI (T2 weighted) imaging. T2-weighted images suggested a mixed population of tumors. A: Showing low signal intensity tumor. B: Extremely high signal intensity tumor.

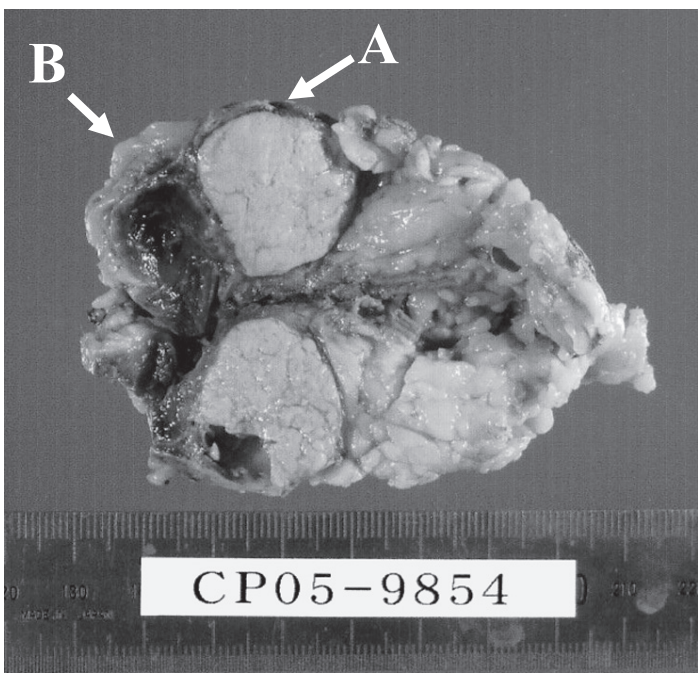

Fig. 3. Histopathological examination macroscopic finding of left adrenal gland. Left adrenal specimen contained two tumors. A: Yellowish round mass measured $24 \times 18$ mm. B: Reddish-brown, well-encapsulated, hemorrhagic medullary mass measured $19 \times 13 \mathrm{~mm}$.

The patient complained of tingling or numbness in the extremities and generalized fatigability postoperatively. Given that this was possibly due to adrenal insufficiency, the patient was given hydrocortisone $100 \mathrm{mg} /$ day intravenously. Four days postoperatively, the patient was put on hormone replacement therapy with hydrocortisone $20 \mathrm{mg}$ /day, with the hydrocortisone dose gradually being titrated down, until the

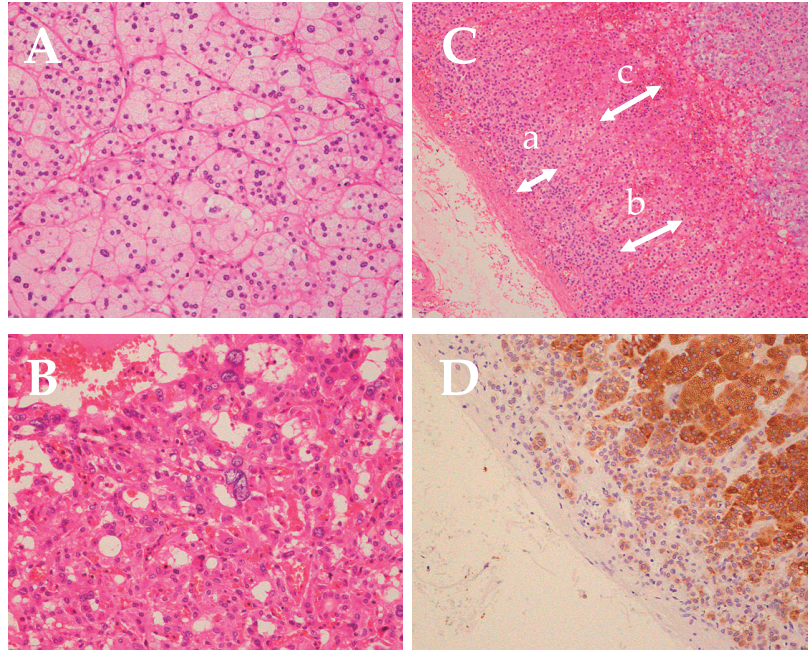

Fig. 4. Microscopic examination. A: Adrenocortical mass (HE stain $\times 100)$. B: Adrenomedullary mass (HE stain $\times 100$ ). C: Attached normal adrenal cortex (HE stain $\times 40$ ). a: zona glomerulosa, b: zona fasciculate, c: zona reticularis. D: Attached normal adrenal cortex (immunohistochemical stain $3 \beta \mathrm{HSD} \times 40$ )

treatment was discontinued after 7 months. Currently, 1 year and 7 months after the operation, her blood pressure remains stable at around $120 / 70 \mathrm{mmHg}$ without anti-hypertensive drug, and hypokalemia improved with the serum potassium level remaining on the order of $4 \mathrm{mmol} / \mathrm{l}$, and all other hormone levels remain within normal ranges (PAC: $4.28 \mathrm{ng} / \mathrm{dl}$; PRA: $0.3 \mathrm{ng} / \mathrm{ml} / \mathrm{hr}$; A: $9.0 \mathrm{pg} / \mathrm{ml}$; NA: $291 \mathrm{pg} / \mathrm{ml}$; DA: $17 \mathrm{pg} / \mathrm{ml})$. 


\section{Discussion}

The present case was referred to our endocrinology clinic with suspected Cushing's syndrome, and was clinically diagnosed as having adrenocortical adenoma producing both aldosterone and cortisol in the left adrenal gland, and underwent left adrenalectomy. However, evidence of temporary elevation of blood pressure during operation also suggested the existence of PC. Indeed, the excised lesion was found to be a double tumor containing both APA and PC. The reason that the diagnosis of PC was not established preoperatively was that the patient showed no typical symptoms compatible with PC, such as paroxysmal elevation of blood pressure and palpitation, and that ${ }^{123}$ I-MIBG scintigraphy performed in 2004 revealed no abnormal uptake. While this negative result was possibly due to the fact that the patient's catecholamine secretion was not high at the time of examination, there is a report [9] suggesting that ${ }^{123}$ I-MIBG scintigraphy may cause false-negative results in rare cases with PC depending on the nature of the tumor being examined and the duration of scintigraphy after radionucleotide injection. In light of that study we should have performed follow up ${ }^{123}$ I-MIBG scintigraphy in 2005. Furthermore, increased NA and DA levels in the preoperative endocrinological examination were judged to be stress-induced, so we did not examine the amount of urinary catecholamine excretion. CT and MRI findings suggested the presence of APA complicated by an adrenal cyst, rather than two different solid tumors. However, while reviewing the laboratory findings retrospectively, we noted that the hematological examination performed November 2002 had already shown an increase in plasma VMA level $(9.8 \mathrm{ng} /$ $\mathrm{ml}$ ). Additionally, a closer examination of the $\mathrm{CT}$ and serial thin-slice MRI imaging findings suggested the presence of two tumors that yielded different imaging results. In particular, serial thin-slice T2-weighted MRI revealed distinct density masses. Thus, we should have considered the possibility of a double tumor as a potential alternative diagnosis before proceeding to surgery.

Whether or not the present adrenocortical tumor had the ability to produce cortisol required a histopathological examination of the tumor. Examination of attached normal adrenal tissue revealed no significant atrophic change of the zona fasciculate and zona reticularis. Furthermore, there was no evidence of inhibition of the HPA axis which led us to conclude that the presence of long-term cortisol excess state was unlikely. Furthermore, immunohistochemical evaluation of the resected tumor tissue revealed that, of all steroid synthetases, $\mathrm{P} 450_{\mathrm{SCC}}, 3 \beta-\mathrm{HSD}, \mathrm{P} 450_{\mathrm{C} 21}$ and $\mathrm{P} 450_{\mathrm{C} 11}$ required for aldosterone synthesis were expressed in the tumor, but $\mathrm{P}_{450} 0_{\mathrm{C} 17}$ required for cortisol synthesis was not, confirming our conclusion that it was unlikely that the tumor had been synthesizing and secreting cortisol in large excess. The cortisol excess state observed preoperatively was thus thought to be due to rapid growth of $\mathrm{PC}$, which stimulated the attached zona fasciculate, leading to steroid overproduction. Another reason is the chronic CRH excess state resulting from the patient's prolonged tension. Since the patient was nervous about adrenal insufficiency, she could not bring herself to discontinue hydrocortisone therapy for 7 months.

Cases of APA co-existing with PC in an ipsilateral adrenal gland are extremely rare [1-4]. Generally, pathogenetic factors that contribute to the development of tumors of both adrenocortical and adrenomedullary origin in an ipsilateral adrenal gland include the following: First, there may exist a population of adrenal tumors characterized by the presence of a mixture of tissues that is of both adrenocortical and adrenomedullary origin. In fact, a mixed form of PC containing adrenocortical tissue has been reported [10]. However, histopathological examination showed that the present case was one of a collision tumor with no tumor tissue found to be of mixed origin, thus ruling out this first possibility of a mixed form of tumor. Second, the adrenocortical hormones may have possibly communicated with the adrenal medulla to regulate catecholamine production. Normally, the glucocorticoids synthesized in the adrenal cortex flow centripetally into the adrenal vein to upregulate the activity of phenyl-ethanolamine-N-methyl-transferase, an enzyme essential for adrenalin production, and then to flow into the adrenal medulla [11]. However, there are no published reports demonstrating that aldosterone overproduction contributes to the development of PC. Therefore, this second possibility is also ruled out. Third, catecholamine oversecretion may have led to secondary aldosteronism due to increased renin production. Catecholamine is known to increase the serum renin concentration via the $\beta 1$ adrenergic receptor [12], thereby elevating serum angiotensin II and aldosterone concentrations. Based on a background of 
catecholamine overproduction, catecholamine may have not merely induced adrenocortical hyperplasia and secondary aldosteronism; it might also have brought about chronic autonomic aldosterone secretion and adenoma development, thus inhibiting renin secretion in turn. As for evidence that supports this hypothesis, it is reported that aldosterone and renin oversecretion may occur in PC [13]; in addition, it is also reported that renin activity becomes inhibited when aldosterone oversecretion continues chronically in patients with renal disease [14]. However, in the present case, no increase in renin activity was noted, hence this possibility was also unlikely. Finally, the present case may have constituted a case of tertiary aldosteronism in which PC produced humoral factors other than catecholamine that induced adrenocortical hyperplasia, thus contributing to the development of adenoma as well as to aldosterone production. In this regard, PC is known to produce a variety of peptides, notably $\mathrm{ACTH}$ as a hormone stimulating aldosterone production [15]. However, in the present case, no increase in plasma ACTH level was observed during the entire clinical course, and this hypothesis was thought unlikely. Taken together, in the present case, APA and PC developed incidentally to co-exist in the ipsilateral adrenal gland. Further study is required to verify whether or not this may be the case in further patients.

In addition, the present case received left adrenalectomy without diagnosis of PC. Anesthetic drugs can exacerbate the life-threatening cardiovascular effects of catecholamines secreted by pheochromocytomas [5], and laparoscopic adrenalectomy for pheochromocytoma results in marked catecholamine release during pneumoperitoneum and tumor manipulation [6]. Patients who receive surgery with undiagnosed PC are thus being exposed to high risk of markedly elevated blood pressure.

Finally, the enlargement of this mass, from $2 \mathrm{~cm}$ to $3 \mathrm{~cm}$ in one year, was considered to be due to rapid cell proliferation of PC. Given the Ki67 index of 4 to $5 \%$ for PC, which did not entirely rule out the possibility that the tumor might recur or metastasize in this patient, careful monitoring and follow-up are required.

Our experience suggested that double lesions consisting tumors of both adrenocortical and adrenomedullary origin might need to be looked for when an adrenal tumor has been detected. Any complication with PC should be carefully diagnosed to lower intraoperative risk of adrenolectomy in a patient with aldosteronism and double adrenal masses.

\section{References}

1. Wilkins GE, Schmidt N, Lee-Son L (1977) Coexistence of pheochromocytoma, adrenal adenoma and hypokalemia. Can Med Assoc J 116: 360-362.

2. Hsieh BS, Chen FW, Hsu HC, Chang CC, Chen WY (1979) Hyperaldosteronism with coexistence of adrenal cortical adenoma and pheochromocytoma. Taiwan $Y i$ Xue Hui Za Zhi 78: 445-451.

3. Wajiki M, Ogawa A, Fukui J, Komiya I, Yamada T, Maruyama Y (1985) Coexistence of aldosteronoma and pheochromocytoma in an adrenal gland. J Surg Oncol 28: $75-78$.

4. Gordon RD, Bachmann AW, Klemm SA, Tunny TJ, Stowasser M, Storie WJ, Rutherford JC (1994) An association of primary aldosteronism and adrenalinesecreting phaeochromocytoma. Clin Exp Pharmacol Physiol 21: 219-222.

5. Myklejord DJ (2004) Undiagnosed pheochromocytoma: the anesthesiologist nightmare. Clin Med Res 2: 59-62.

6. Joris JL, Hamoir EE, Hartstein GM, Meurisse MR, Hubert BM, Charlier CJ, Lamy ML (1999) Hemodynamic changes and catecholamine release during laparoscopic adrenalectomy for pheochromocytoma. Anesth Analg 88: 16-21.

7. Weiss LM (1984) Comparative histologic study of 43 metastasizing and nonmetastasizing adrenocortical tumors. Am J Surg Pathol 8: 163-169.

8. Sasano H (1994) Localization of steroidogenic enzymes in adrenal cortex and its disorders. Endocr $J$ 41: 471-482.

9. Lindberg S, Fjälling M, Jacobsson L, Jansson S, Tisell LE (1988) Methodology and dosimetry in adrenal medullary imaging with iodine-131 MIBG. J Nucl Med 29: 1638-1643.

10. Mathison DA, Waterhouse CA (1969) Cushing's syndrome with hypertensive crisis and mixed adrenal cortical adenoma-pheochromocytoma (corticomedullary adenoma). Am J Med 47: 635-641.

11. Axelrod J (1975) Relationship between catecholamines and otehr hormones. Recent Prog Horm Res 31: 1-35.

12. Reid IA, Schrier RW, Earley LE (1972) An effect of extrarenal beta adrenergic stimulation on the release of renin. J Clin Invest 51: 1861-1869.

13. Wilson RJ, Craig GM, Mills IH (1973) Metabolic stud- 
ies in a patient with a phaeochromocytoma associated with hypokalaemia and hyperaldosteronism. J Endocrinol 56: 69-78.

14. Baer L, Sommers SC, Krakoff LR, Newton MA, Laragh JH (1970) Pseudo-primary aldosteronism. An entity distinct from true primary aldosteronism. Circ
Res 27(1 suppl 1): 203-220.

15. Tan GH, Carney JA, Grant CS, Young WF Jr (1996) Coexistence of bilateral adrenal phaeochromocytoma and idiopathic hyperaldosteronism. Clin Endocrinol 44: 603-609. 